\author{
Anselmo Peres Alós \\ Universidade Federal de Santa Maria
}

\title{
Sexualidades marginais nas bordas do texto: cinema, política e performatividade de gênero em El beso de la mujer araña
}

\begin{abstract}
Resumo: Este artigo pretende discutir algumas das ambivalentes relações entre cinema, política e performatividade de gênero no romance El beso de la mujer araña lO beijo da mulheraranha], romance argentino escrito por Manuel Puig e publicado pela primeira vez em 1976. Embora esse romance não seja o primeiro a problematizar gênero e performatividade no contexto da literatura latino-americana, ele apresenta um enredo particularmente subversivo no que diz respeito à representação de rupturas no interior dos preceitos heteronormativos. Palavras-chave: gênero; performatividade; Manuel Puig; cinema; literatura latino-americana.
\end{abstract}

Copyright (c) 2013 by Revista Estudos Feministas.

1 Daniel YAKER e Manuel PUIG, 1985 , p. 208

2 Inúmeras traduções do romance já foram editadas em português. Destacam-se as traduções brasileiras publicadas pelas editoras CODECRI, Círculo do Livro e Rocco (PUIG, 1980, 1981 e 1986, respectivamente). Por considerar-se aqui a língua original do romance um dos elementos estruturadores fundacionais para a sua significação, e por se entender a tradução como um processo que, em vários sentidos, altera, deforma ou recria o texto literário (Tania Franco CARVALHAL, 2003; Sara Viola RODRIGUES, 2004 e Susan BASSNETT, 2005), optou-se por manter as citações do romance de Puig em castelhano.

\section{Considerações iniciais: intertextos fílmicos "En la vida te tienen que coger bien al menos una vez;
si no vuelve a ocurrir, no importa: vives de ese recuerdo" \\ (Manuel Puig')}

El beso de la mujer araña ${ }^{2}$ está entre aqueles romances latino-americanos que dispõem de uma vasta fortuna crítica, o que já levou críticos como José Amícola a considerar tal romance como obra de Weltliteratur. ${ }^{3}$ Publicado pela primeira vez em 1976, El beso de la mujer araña é o quarto romance de Manuel Puig. Todavia, é no ano de 2002 que surge uma edição de importância singular: trata-se da edição crítica organizada por José Amícola e Jorge Panesi para a Colección Archivos, ${ }^{4}$ projeto da Association Archives de la Littérature Latino-Américaine, des Caraïbes et Africaine du XXème Siècle (ALLCAXX), organização não governamental patrocinada pela UNESCO. Tal edição configura-se como obra crítica de cunho genético-filológico, incluindo não 


\begin{abstract}
${ }^{3}$ José AMíCOLA, 2002, p. xix. ${ }^{4}$ A Colección Archivos é um projeto da Association Archives de la Littérature Latino-Américaine des Caraïbes et Africaine du XXème Siècle, organização não governamental da UNESCO, cuja principal função é a manutenção e o estudo dos manuscritos literários latino-americanos do século XX. Os volumes da coleção, amparados por uma mirada genética na organização das edições críticas, têm colaborado para redimensionar a compreensão da literatura latinoamericana e suas relações com os cânones da literatura ocidental. ${ }^{5}$ Alan PAULS, 2002, p. xvi.
\end{abstract}

\footnotetext{
- AMíCOLA, 2002, p. xxiii tradução nossa.
}

${ }^{7}$ Mieke BAL, 1997, p. 10-18.

${ }^{8}$ BAL, 997, 2000. apenas as diferentes variantes manuscritas e datilografadas, mas também um conjunto de pré-textos, isto é, anotações e investigações realizadas por Puig paralelamente à escrita do romance.

Constantemente, os críticos da obra de Manuel Puig referem-se aos personagens de El beso de la mujer araña como 'o homossexual' (Molina) e 'o guerrilheiro' (Valentín). Pode aqui ser mencionado, apenas a título de ilustração, o escritor argentino Alan Pauls, que caracteriza o referido romance como "una suerte de diálogo socrático entre un militante obcecado y una loca demodée". 5 José Amícola, por sua vez, considera esse tipo de leitura bastante arriscado e reducionista, na medida em que aponta para uma interpretação essencialista das identidades sociais em questão:

El hecho de que las publicaciones más recientes que lucham contra los estereotipos sexuales siguieron utilizando un término como "homosexual" pareció revelar, con todo, hasta qué punto seguimos andados en esta designación que al parecer data de 1860 y de la que no parecemos todavía capaces de liberarnos. ${ }^{\circ}$

Assim como é possível falar em narrativas encaixadas, ou em mise-en-abîme narrativo, também é possível falar em uma focalização encaixada. ${ }^{7}$ Em outras palavras, mesmo com a autonomia dada aos personagens com a utilização do discurso direto e a ausência de uma voz tirânica e monolítica, é possível de se pensar em um sujeito focalizador, entendido não como uma consciência individual, ou como uma voz narrativa, mas sim como um lugar de articulação de valores.

O narrador é a instância que define, a partir das diferentes maneiras pelas quais pode ter sua presença indicada no texto, características específicas desse texto. Acoplada à questão do narrador, está a questão da focalização: juntos, narrador e focalização determinam o que se conhece por narração. A identidade do narrador e a focalização de uma narrativa estão estreitamente relacionadas, mas não se confundem. Tal confusão provém da ideia de que a linguagem carrega sempre uma visão de mundo. Entretanto, se o narrador tem sua identidade definida pelas estratégias textuais, a focalização está, por sua vez, ligada à maneira pela qual os eventos que constituem a fábula são apresentados. É a partir do momento em que se consegue discernir o status diferenciado do narrador e do processo de focalização que se compreende as diferentes manifestações dos agentes narrativos em cada um dos níveis de análise. ${ }^{8}$ Nesse sentido, pode-se afirmar, sem receio de equívoco, que tanto Valentín quanto Molina configuram-se como dois diferentes focalizadores.

1122 Estudos Feministas, Florianópolis, 21(3): 1121-1147, setembro-dezembro/2013 
9 O camp funciona com um 'solvente da moralidade', isto é, baseia-se na descoberta de que a sensibilidade da cultura erudita não detém o monopólio do refinamento. Segundo Susan Sontag "a questão fundamental do camp é destronar o sério. O camp é ocoso, anti-sério. Mais precisamente, o camp envolve uma nova e mais complexa relação com o 'sério'. Pode-se ser sério a respeito do frívolo, e frívolo a respeito do sério" (Susan SONTAG, 1987, p 332). Denilson Lopes, por sua vez, relê o camp nos seguintes termos: "como comportamento, o camp pode ser comparado à fechação, à atitude exagerada de certos homossexuais, ou simplesmente à afetação. Já como questão estética, o camp estaria mais na esfera do brega assumido, sem culpas, tão presente nos exageros de muitos dos ícones da MPB, especialmente no culto a certas cantoras e seus fãs" (LOPES, 2002, p. 95). 10 SANGUE DE PANTERA (Cat People). Direção de Jacques Tourneur. Elenco: Simone Simon, Kent Smith, Tom Conway, Jane Randolph e Jack Holt. Estados Unidos, 1942. (73 $\mathrm{min}) 35 \mathrm{~mm}$. "PUIG, 1994, p. 9. Todas as referências ao romance, neste artigo foram feitas a partir desta edição. ${ }^{12}$ PUIG, 1994, p. 11.
Além desses dois focalizadores (que se configuram através da focalização interna), é oportuno ressaltar a existência de um focalizador externo, o qual diz respeito ao 'narrador' que emerge na organização das notas de rodapé.

O primeiro focalizador importante a ser destacado é Molina. Sua afetação, sua 'frivolidade' e sua percepção camp ${ }^{9}$ do mundo são as lentes através das quais o personagem recriará os filmes hollywoodianos que contará para Valentín, como modo de distraí-lo nas intermináveis horas compartilhadas na cela. Cabe uma breve análise de dois desses filmes contados por Molina a Valentín, uma vez que, através da recriação dos filmes pela oralidade, torna-se possível apreender um pouco das maneiras pelas quais Molina compreende a divisão social dos gêneros. Na primeira das narrativas, é recriado por Molina o filme Sangue de pantera, história de horror cuja protagonista é Irena, ${ }^{10}$ uma jovem que acredita ser descendente de uma família amaldiçoada. Sua sina é a de, em momentos de tensão emocional, transformar-se em pantera e cometer assassinatos. A descrição feita por Molina da personagem Irena acentua os traços da femme fatale:

[lrena] parece muy jóven, de unos veinticinco años cuanto más, una carita un poco de gata, la nariz chica, respingada, el corte de cara es... más redondo que ovalado, la frente ancha, los cachetes también grandes pero que después se van para abajo en punta como los gatos. ${ }^{11}$

As tintas usadas por Molina para recriar a personagem Irena acentuam a sua animalidade, a semelhança de seus traços com os traços de uma gata. A jovem é uma imigrante sérvia, nascida em um vilarejo da Transilvânia, "donde viven las fieras que en invierno se enloquecen de hambre y tienen que bajar a las aldeas, a matar". ${ }^{12}$

Em uma tarde no zoológico, a jovem conhece um arquiteto americano, por quem se enamora. Ela teme ser descendente das mulheres-panteras e, após beijar o homem que ama, transformar-se em fera e o estraçalhar com garras e dentes, de modo que os dois se casam, mas não se tocam. A estreita amizade do marido com outra arquiteta, uma colega de trabalho, desperta os ciúmes de Irena. Ao final do filme, uma pantera foge do zoológico e Irena é encontrada morta, em frente à jaula, enquanto o marido afasta-se do lugar abraçado com a arquiteta. Nos filmes hollywoodianos dos anos 40 , o beijo pode ser lido como uma figura metonímica a sinalizar o encontro sexual. Dessa forma, o medo de Irena será interpretado por Valentín, após ouvir a narrativa de Molina, a partir de uma perspectiva freudiana, como sintoma de frigidez sexual. 


\begin{abstract}
${ }^{13}$ Este filme é uma criação fictícia e intradiegética de Puig, inspirado nos filmes expressionistas alemães dos Estúdios UFA, particularmente Die Grosse Lieb [O Grande Amor], de 1942 , e com referências aos filmes de espionagem dos anos 1930 , como aqueles protagonizados por Marlene Dietrich e Greta Garbo. Para uma análise mais aprofundada das apropriações cinematográficas realizadas por Manuel Puig, conferir Graciela ESPERANZA, 2002, p. 550-563.
\end{abstract}

${ }^{14}$ PUIG, 1994, p. 94.
A segunda narrativa de Molina é construída a partir de um filme de propaganda nazista, intitulado Destino. ${ }^{13}$ Nesse filme, que retrata uma história de amor no período da invasão nazista na França, a cantora francesa Leni Lamaison apaixona-se por Werner, um oficial alemão do Terceiro Reich. Leni nasceu na Alsácia, território alemão conquistado pela França e anexado como parte do Estado Nacional francês. Essa identidade, marcada por um entrelugar francogermânico, complexifica os sentimentos de Leni. Seduzida pelos ideais do Reich e pelos olhos azuis de Werner, ela inicia uma temporada de intensos estudos em Berlim e acaba por entrar em um comando de espionagem nazista. Ao retornar para a França, começa a observar sua pátria com novos olhos: "en efecto, acostumbrada ya al sol que resplandece en los rostros de la Patria Nacional Socialista, le disgusta ver su Francia así envilecida como está por las contaminaciones raciales. Su Francia le parece innegablemente negrificada e judía". ${ }^{14}$ Em meio a uma operação de espionagem, Leni é baleada pouco antes da chegada de Werner e morre nos braços do oficial alemão. É importante salientar aqui o movimento contraditório que está na gênese da constituição de Leni Lamaison: filha de um entrelugar, resultante da mescla entre a cultura germânica e a cultura francesa, ela passa a atuar em nome da 'pureza racial' almejada pelo ideário do Terceiro Reich.

A maneira através da qual Molina recria os filmes diz muito sobre sua percepção de uma maneira mais ampla, a qual não fica restrita ao caráter liminar da identidade nacional de suas heroínas. Nos dois filmes em questão, a mulher é representada como uma femme fatale. Contudo, estas femmes (Irena e Leni) não são fatais senão para elas mesmas, uma vez que morrem ao final das narrativas, enquanto seus parceiros permanecem vivos, ratificando o lugar dos homens na sociedade e a subordinação das mulheres aos esquemas patriarcais da cultura. Além disso, como já afirmou em outra oportunidade Francine Masiello, ambas possuem identidades que desde suas origens mostram-se 'contaminadas', híbridas e cruzadas: "Irena proviene de Transilvania, Leni [...] de Alsácia: ambas son originales de zonas de identidad cruzadas, regiones donde reina la hibridación". ${ }^{15}$ Através da recriação oral de Sangue de pantera, evidencia-se o fato de que Molina associa o feminino a ideias de obscuridade, animalidade e natureza, enquanto através de Destino emerge uma mulher passional que trai sua pátria em nome do amor por um oficial alemão. ${ }^{16}$ As representações da mulher nas quais Molina se inspira para constituir a sua própria performance de gênero feminino são trágicas, são mulheres que veem a si mesmas como mulheres de ação ${ }^{17}$ (ainda que isso não seja a garantia da representação de um modelo de feminilidade fora dos

1124 Estudos Feministas, Florianópolis, 21(3): 1121-1147, setembro-dezembro/2013 


\footnotetext{
${ }^{19} \mathrm{~A}$ discussão da problemática envolvendo a dicotomia forma e conteúdo, bem como suas consequências para a análise e a interpretação de narrativas literárias e fílmicas, possui uma longa fortuna crítica. Cabe mencionar, como síntese fundamental dessa discussão, Austin WARREN e René WELLEK (1971a e 1971b). Para um olha mais aprofundado sobre a questão do valor artístico de artefatos culturais narrativos, do ponto de vista das origens desta discussão, ver também Ralph B. PERRY (1926) John LAIRD (1929) e Orlie A. PELL (1930).
}

estereótipos construídos por Hollywood), abrindo espaço para, assim, assegurar a este feminino a possibilidade de intervenção no espaço público. Ao contrário da trajetória de Irena, a história do envolvimento de Leni Lamaison com a espionagem e o Terceiro Reich não é contada por Molina, mas sim por uma nota de rodapé, creditada ao serviço de divulgação do estúdio produtor do filme Destino. Isso implica, pois, no reconhecimento de que o tom nazista apresentado pelo filme não coincide com os valores de Molina. Ele modaliza os conteúdos pró-nazistas do filme, apagando os estereótipos raciais nele encontrados, os quais são reintroduzidos pelo narrador das notas de rodapé, ao mencionar o material publicitário veiculado pelo filme. Esse dado evidencia, portanto, que Molina possui algum conhecimento acerca dos valores revolucionários de Valentín, e do fato de que o guerrilheiro não compactuaria com o ideário nazista do filme. Apesar do esforço investido por Molina, Valentín mostrase revoltado pela ideologia nazista explicitamente veiculada pelo filme. Molina faz questão de salientar que são os efeitos estéticos e a história de amor, e não os aspectos políticos do filme, que lhe agradam: "pero tené bien claro que la película era divina por las partes de amor, que eran un verdadero sueño, lo de la política se lo habrán impuesto al director los del gobierno, ¿o no sabés cómo son esas cosas?". ${ }^{18}$ Para Molina, há um completo divórcio entre cinema (artefato cultural) e política (os valores veiculados pelo artefato). A ideologia nazista do filme Destino é vista como um aspecto menor, desimportante, 'imposto pelos homens do governo', uma vez que a plasticidade das imagens e as emoções suscitadas pela história de amor são hipervalorizadas. Em contrapartida, Valentín não consegue dissociar o caráter estético do filme das reverberações políticas pró-nazistas nele implicadas. Sob a rasura da discussão em torno do juízo de valor acerca da questão da traição, emerge aqui uma discussão bem mais interessante, que é a da articulação entre forma e conteúdo. Enquanto Valentín mostra-se consciente da indissociabilidade da articulação entre forma e conteúdo nos processos de significação (e, nesse sentido, o drama sentimental é uma forma eficiente para realizar a propaganda nazista doutrinária que se espera de um filme como Destino), Molina insiste na dissociação entre forma e conteúdo, ao minimizar a importância de que a história de amor que se conta em Destino esteja subordinada aos imperativos nazistas. Ambos os personagens refutam os valores veiculados pela ideologia nazista, mas Molina não se apercebe do fato de que sua admiração como espectador pelo filme é indice de seu assujeitamento pelo discurso fílmico. ${ }^{19}$

Outro aspecto importante em relação ao filme Destino é o fato de que a nota de rodapé que o apresenta dialoga 
com a apresentação, no texto principal do romance, dos primeiros indícios de que Molina está acumpliciado com o Comissário de Polícia responsável pelo encarceramento de Valentín, tentando arrancar informações relacionadas a ações terroristas, subversivas e/ou revolucionárias, bem como os nomes dos outros cúmplices do guerrilheiro. Molina, que a princípio aceita esta função de espião e de delator dos segredos de Valentín em troca da diminuição de sua pena, será, ao final do romance, cúmplice de seu companheiro de cela, aceitando a missão de levar informações aos outros companheiros do guerrilheiro. Leni Lamaison trai sua pátria em nome do amor e acaba morrendo nos braços do seu amado durante a missão de espionagem; Molina trai a confiança do Comissário do presídio, levando informações para o grupo revolucionário, e, em sua missão, também acaba sendo assassinado. Como uma estrela de cinema dos filmes que tanto the aprazem, Molina prefere ser morto pelos companheiros de Valentín em uma 'queima de arquivo' a correr o risco de ser pego pela polícia e ter de o delatar.

\section{Molina, uma mulher performativamente aracnídea}

Inevitável se torna a associação entre os personagens Luis Alberto Molina e Leni Lamaison: ela trai sua pátria por amor a um oficial estrangeiro, enquanto ele, de certa forma, também 'trai' sua pátria argentina (considerando os interesses argentinos do ponto de vista do governo ditatorial, perseguidor de revoltosos como Valentín), colaborando com a resistência revolucionária por amor a um guerrilheiro. Ad argumentandum tantum, o fato de ser esta traição louvável ou condenável é um julgamento de valor que não a descaracteriza em sua natureza de traição à pátria, uma vez que, para Molina, o amor romântico fala mais alto do que as filiações de cunho político. O irônico da analogia reside no deslocamento da modulação ideológica da ação de Leni (que se transforma em colaboradora nazista), com relação à modulação ideológica das ações de Molina, que auxilia a guerrilha revolucionária antiditatorial. Tanto Leni quanto Molina encontram a morte como resultado de suas traições, mortes que são motivadas, ao mesmo tempo, pela causa que decidem abraçar e pelos homens que decidem amar. Pensar nessa simultaneidade das ações de Leni e Molina implica pensar também no quanto as dimensões do público, do privado, do pessoal e do político estão entrelaçadas.

Quanto ao seu gênero e à sua sexualidade, Molina não se percebe como um homem, tampouco como um homossexual. Ao pensar nos imbricados aspectos que se estabelecem entre identidade de gênero e orientação sexual, 
${ }^{20}$ Néstor PERLONGHER, 1986, p. 3-4.

${ }^{21}$ PUIG, 1994, p. 68, grifo meu.

22 PUIG, 1994, p. 69, grifo meu.

${ }^{23}$ Roberto ECHEVARRÉN, 2002, $\mathrm{p}$. 462.

${ }^{24}$ ECHEVARRÉN, 2002, p. 462. poderia ser Molina considerado uma 'mulher heterossexual'? Néstor Perlongher apercebe-se disso, problematizando a operacionalização de uma categoria como 'homossexualidade' nas leituras do romance de Manuel Puig: "si se entiende por homosexualidad a la relación entre dos hombres, ¿qué pasa cuando uno de los sujetos 'masculinos' se reclama 'mujer'?". ${ }^{20}$ Quando Molina começa a contar a Valentín sobre o homem casado com quem se encontrava, declina-se no feminino: "a la semana siguiente fui sola al restaurant". ${ }^{21}$ Ao estranhamento de Valentín ao ouvir Molina referir-se a si mesmo no feminino, Molina responde: "perdóname, pero cuando hablo de él yo no puedo hablar como hombre, porque no me siento hombre". ${ }^{22}$

Para compreender Molina como focalizador, é necessário levar em consideração esses fatores complicadores que entram em jogo na articulação de sua subjetividade. Poderse-ia argumentar que o fato de Molina reivindicar para si uma identidade feminina, referir-se a si mesmo no feminino e apaixonar-se reiteradamente por homens heterossexuais não o convertem materialmente em uma mulher heterossexual. Como contraponto, pode-se pensar no próprio Valentín que, por ocasião das noites em que faz amor com Molina, tampouco 'transforma-se' em um homem homossexual. Como pensar, então, nesses personagens, uma vez que as categorias de gênero (homem e mulher, ou ainda, masculino e feminino) e as de orientação sexual (heterossexualidade e homossexualidade) não conseguem dar conta das subjetividades desses personagens? A performance de Molina, ao invés de subscrever o caráter binário dos códigos de sexo e de gênero, questiona a própria possibilidade de uma matriz dicotômica a produzir identidades de gênero e de sexualidade, ao mostrar o quanto são frágeis os seus limites classificatórios.

Como dar conta da indisciplinada identidade de gênero desses dois personagens, indóceis a qualquer tentativa de classificação ou de descrição normalizadora? O crítico uruguaio Roberto Echevarrén levanta a seguinte questão acerca da identidade sexual de Molina: "me llamó la atención que el tipo de homosexual que describe la novela correspondiera a una generación anterior [a la mía]". ${ }^{23}$ Mais adiante, ele continua:

[Puig] evocaba la atmósfera tradicional más que el contexto de activismo político que experimentábamos [en los años setenta]. El énfasis en las identidades femeninas se me ocurría ligeramente anacrónico a la mayor alternancia de roles que por entonces se promovía y ensayaba. ${ }^{24}$

Mais produtivo do que discutir se Molina encarna ou não uma persona masculina e homossexual, ou uma persona 
25 Judith BUTLER, 2004.

${ }^{26}$ Sobre a questão da crítica queer na América Latina, conferir Anselmo Peres ALÓS, 2010, $2011 \mathrm{a}$ e $2011 \mathrm{~b}$ ${ }_{27}$ BUTLER, 1993, 2003, 2004a e 2004b.

${ }^{28}$ Eve Kosofsky SEDGWICK, 1985 e 1990. feminina e heterossexual, é avaliar de que maneiras os binarismos de gênero e de orientação sexual são denunciados como ficções reguladoras da identidade humana.

O movimento de liberação gay das décadas de 1970 e 1980, ao valorizar expressões plurais da hipermasculinidade como forma de rechaço à homofobia, terminou, paradoxalmente, por realizar a manutenção de preceitos heteronormativos. Ao se valorizarem expressões masculinizadas de identidades homossexuais, tais como os corpos trabalhados à exaustão em academias de ginástica, continuou-se associando as expressões efeminadas da homossexualidade a uma noção transcendental que coloca o feminino em uma posição subordinada ao masculino. Analogamente, as estratégias de hipermasculinização das identidades homossexuais excluíram das discussões, juntamente com os homens homossexuais efeminados, as lésbicas de maneira geral, incidindo muitas vezes na reprodução e manutenção de preconceitos misóginos. Ao enfocar o combate à discriminação por orientação sexual, perdeu-se de vista o aspecto de preconceito de gênero, o qual muitas vezes permeia a discriminação por orientação sexual. Manuel Puig, ao dar destaque a um personagem homossexual que se declina no feminino, em um momento histórico no qual a associação entre homossexualidade masculina e feminilidade estava sendo combatida pelos movimentos homossexuais, traz de volta para a discussão a importância de se problematizar gênero e orientação sexual simultaneamente. A construção do personagem Molina, modulada pelas representações estereotipadas das identidades femininas de gênero, consegue - paradoxalmente - questionar os regimes normativos da homossexualidade, ao mesmo tempo que rompe com os pressupostos da matriz heterossexual. Nesse sentido, o personagem Molina cumpre um importante papel ao desestabilizar a homonormatividade, isto é, a hegemonia de formas assimilacionistas de se viver a homossexualidade. ${ }^{25}$

Ainda que seja a orientação adotada no presente trabalho, implicaria um gesto de desonestidade intelectual não sinalizar as críticas que a teoria queer sofre em alguns setores do campo acadêmico. ${ }^{26} \mathrm{O}$ grande prejuízo de um projeto interpretativo calcado nas premissas queer estaria, de acordo com os seus críticos, no fato de que a teoria da performatividade, tal como formulada por Judith Butler ${ }^{27}$ e Eve Kosofsky Sedgwick, ${ }^{28}$ supostamente ruiria com a plataforma conquistada pelos movimentos sociais cujo objetivo foi a liberação sexual. De acordo com Leo Bersani, "ressignification cannot destroy; it merely presents to the dominant culture spectacles of politically impotent disrespect" [o ato de ressignificação é incapaz de destruir; ele apenas apresenta à cultura dominante espetáculos culturais de um desrespeito 
29 Leo BERSANI, 1995, p. 51 , tradução minha.

${ }^{30}$ BERSANI, 1995, p. 71, tradução minha. ${ }^{31}$ BUTLER, 1993, p. 240 , tradução
minha.

${ }^{32}$ BUTLER, 1993, p. 240-241 tradução minha.

${ }^{33}$ BUTLER, 2004a, p. 102-130.

${ }^{34}$ Calvin THOMAS, 2002 , p. 27, tradução minha. politicamente impotente]. ${ }^{29}$ Ainda segundo Bersani, as políticas performativas de resistência e subversão denotam "a potentially revolutionary inaptitude - perhaps inherent in gay desire - for sociality as it is know" [uma potencial inaptidão revolucionária - talvez inerente ao desejo gay - para a sociabilidade tal como conhecida]..$^{30}$ De maneira curiosa e sintomática, a própria Judith Butler responde a essas questões, três anos antes de Bersani as formular: "the goal of this analysis then cannot be pure subversion, as if an undermining were enough to establish and direct political struggle. [...] But how, also, to rethink the terms that establish and sustain bodies that matter?" [o objetivo deste tipo de análise então não pode ser a pura subversão, como se um enfraquecimento fosse suficiente para estabelecer uma reivindicação política direta. [...] Mas como, então, repensar os termos e legitimar os corpos que possuem materialidade e importância?]. ${ }^{31}$ A pergunta retórica é respondida em seguida: "in the reformulation of kinship, in particular, the redefinition of the 'house' and its forms of collectivity, mothering, mopping, reading and becoming" [na reformulação do parentesco, em particular na redefinição da "casa" e de suas formas de coletividade, maternação, fricção, leitura e transformação]..$^{32}$ Tal como se pode depreender de obra posterior da filósofa estadunidense, essa "reformulação do parentesco" deve ser entendida no sentido de um dilatamento da noção, de maneira a poder incluir, sob a rubrica do parentesco, arranjos familiares que não estejam calcados no modelo heteronormativo de família nuclear. ${ }^{33}$

Ao contrário do que afirma Leo Bersani, os esforços políticos implicados nas teorizações dos estudos queer vêm produzindo importantes formulações na redefinição das identidades heterossexuais. Em Straight with a Twist: Queer Theory and The Subject of Heterosexuality, volume de artigos organizado por Calvin Thomas, observa-se o questionamento da heteronormatividade a partir de um locus de enunciação queer: "straights have had the political luxury of not having to think about their sexuality, in much the same way as men have not had to think of themselves as being gendered and whites not had to think of themselves as raced" [os heterossexuais possuem, desde sempre, o luxo político de não ter de pensar sobre a sua própria sexualidade, mais ou menos da mesma maneira que os homens não precisam pensar a si próprios como sujeitos gendrados e os brancos não precisam pensar em si mesmos como sujeitos racializados]. ${ }^{34}$

Somando-se ao grande destaque do personagem Molina a invisibilidade ou 'inexistência' de um narrador externo (o qual está presente tão somente nas notas de rodapé), torna-se compreensível a recorrência de leituras desse romance que tentam, de alguma forma, fazer com que Molina ocupe o lugar dessa voz narrativa ausente. 
${ }^{35}$ PUIG, 1994, p. 21.

${ }^{36}$ PUIG, 1994, p. 23.

${ }^{37}$ PUIG, 1994, p. 23.
Destarte, o que caracteriza Molina como um dos focalizadores no romance pode ser descrito como a percepção de um homossexual em um contexto particularmente homofóbico (uma ditadura latino-americana na década de 1970). É também a percepção de um homem que se coloca socialmente como mulher, isto é, que performativiza uma identidade de gênero e de orientação sexual calcada no feminino. Nesse sentido, o caráter performativo do gênero feminino de Molina não se reduz à frivolidade de um homossexual, mas também realiza uma paródia dos regimes hegemônicos de masculinidade e de feminilidade. Em última instância, o comportamento 'frívolo' de Molina é tão subversivo, questionador e revolucionário no campo social das relações de gênero quanto o de Valentín o é no campo da resistência política ao regime ditatorial argentino.

Como focalizador e como personagem, Valentín reivindica para si dois privilégios cognitivos: 1) o de conhecer as faces da tortura de uma maneira que Molina jamais vai conhecer e 2) o de conhecer a verdadeira 'natureza' da orientação sexual de seu companheiro de cela. A tortura, violência imposta sobre o corpo politicamente indisciplinado, é algo inominável, uma faceta do real impossível de ser conhecida unicamente através do discurso: somente a compreende quem a experiencia, segundo Valentín. Ele não se contenta em ser mero ouvinte, intervindo várias vezes na narrativa de Molina: "no soy un tipo que sepa escuchar demasiado, ¿sabés, no?, y de golpe me tengo que estar te escuchando callado horas" ${ }^{35}$, diz o guerrilheiro. Em meio à discussão gerada pelas interrupções, Molina se pergunta: "¿por qué no me habrá tocado de compañero el novio de la mujer pantera, en vez de vos?". ${ }^{36}$ Valentín, ao ser deparado explicitamente com a sexualidade do companheiro de cela, encerra a discussão ao afirmar que "yo ya sé todo de vos, aunque no me hayas contado nada". ${ }^{37}$

A homossexualidade, ainda que seja também uma prática cuja definição está ligada ao exercício corpóreo (pelo viés do prazer e da libido), não careceria de experimentação para ser compreendida. Para Valentín, ela é tida como um objeto de conhecimento per se, sem necessidade de experimentação, e tal natureza é atribuída à homossexualidade pelos heterossexuais. Qual é a lógica cognitiva (senão epistemológica) que está em jogo quando Valentín reivindica para si mesmo a prerrogativa de conhecer tanto a natureza da tortura quanto a da homossexualidade? Essa pergunta adquire especial sentido quando se mantém em mente que Molina não detém prerrogativa cognitiva nenhuma, nem mesmo a de conhecer as motivações de sua própria orientação sexual. Operase aqui o que poderia ser descrito como uma 'descorporificação' da sexualidade: comparada à tortura, ela deixa de ser

1130 Estudos Feministas, Florianópolis, 21(3): 1121-1147, setembro-dezembro/2013 
${ }^{38}$ PUIG, 1994, p. 95.

uma experiência corpórea e passa a configurar um mero objeto de especulação imaginativa.

Para falar de si mesmo, Molina recorre a um discurso que não é seu, mas sim de um outro (o discurso do senso comum, que considera a heterossexualidade a única expressão sexual legítima), para poder fazer de si mesmo um ente inteligível. Ele antecipa, em sua própria voz, os argumentos que tantas vezes ouviu sobre as origens dos comportamentos homossexuais afeminados, e que acredita que sejam os fatores 'causadores' da homossexualidade:

[Molina] - Sí, claro. Y ahora te tengo que aguantar que me digas lo que dicen todos.

[Valentín] - A ver... ¿qué te voy a decir?

[Molina] - Todo igual, me viene con lo mismo, isiempre!

[Valentín] - ¿Qué?

[Molina] - Qué de chico me mimaron demasiado, y por eso soy así, pero que siempre se puede uno enderezar, y que lo que me conviene es una mujer, porque la mujer es lo mejor que hay.

[Valentín] - Te dicen eso?

[Molina] - Sí, y eso les contesto... irégio!, ide acuerdo!, ya que las mujeres son lo mejor que hay, yo quiero ser mujer. $^{38}$

A resistência inicial de Valentín a ouvir Molina falar sobre seu desejo, isto é, sobre o seu desejo pelo reconhecimento de sua orientação sexual, é expoente de um importante mecanismo homofóbico. Sair do armário é uma postura performativa, um ato de linguagem: somente é possível sair do armário com sucesso na medida em que um interlocutor aceite o efeito social produzido pelo 'assumir-se'. Uma vez que esse interlocutor aceita e reconhece este efeito performativo, ele se vê, ainda que indiretamente, implicado na homossexualidade do outro. No momento em que Valentín recusa-se a ouvir Molina falar sobre sua homossexualidade, ele realiza um gesto de 'autopreservação' de sua própria identidade heterossexual, posto ser a heterossexualidade o pressuposto de uma identidade social 'guerrilheira' ou 'revolucionária'. Vale lembrar que, historicamente, o marxismo julgou a homossexualidade como um excesso da decadência dos valores burgueses, vendo todos os homossexuais (homens e mulheres) como pessoas frívolas e reacionárias. Valentin, 'desreconhecendo' o ato fundacional da identidade de gênero de Molina (o 'assumir-se'), deslegitima a possibilidade de uma existência social para seu companheiro de cela. 
${ }^{39}$ PUIG, 1994, p. 25.

${ }^{40}$ WITTIG, 2002, p. 21-32

${ }^{41}$ PUIG, 1994, p. 25.

42 PUIG, 1994, p. 33.

\section{Gênero, política e performatividade}

Em uma sociedade na qual a gênese da libido e da orientação sexual é presumidamente heterossexual, um homem que reivindique expressar sua libido em direção a outro homem e constituir sua identidade de gênero como persona feminina é identificado como um sujeito anômalo, anormal e desviante. Por consequência, há a necessidade de que se encontre uma gênese para esse 'desvio da libido'. Tal necessidade, a de narrar uma origem ou causa para o desejo homossexual, é imposta de alguma forma, uma vez que apenas quando comparada à orientação heterossexual é que a homossexualidade é considerada desviante. Como diz Molina, "ahorrame de escuchar consejos, porque yo sé lo que me pasa y lo tengo todo clarísimo en la cabeza". ${ }^{39}$ Todavia, cabe sublinhar que a prerrogativa das definições de normalidade e anormalidade são pertencentes a esse domínio do saber hegemônico que Monique Wittig denominou com perspicácia de mentalidade hetero. ${ }^{40}$

Se para Molina tudo está claro, o mesmo não ocorre com Valentín: "yo no lo veo tan claro, por lo menos como acabás de definir vos". ${ }^{41}$ Valentín lança mão de uma ignorância estratégica, uma vez que conhecer ou compreender algo sobre a homossexualidade é equivalente a com ela 'comprometer-se' de alguma forma. Ao princípio do segundo capítulo, Valentín usa explicitamente o recurso à ignorância, mas em um sentido inverso, de maneira a deslegitimar o privilégio cognitivo reivindicado por Molina acerca da tortura:

[Valentín] - Todo lo que puedo aguantar acá, que es bastante, ... pero que es nada si pensás en la tortura, ... que vos no sabés lo que es.

[Molina] - Pero me puedo imaginar.

[Valentín] - No, no te lo podés imaginar... ${ }^{42}$

Valentín não reconhece nem mesmo a imaginação de Molina sobre a tortura como mecanismo cognitivo válido para realizar uma aproximação do significado da tortura. Entretanto, todo o conhecimento detido por Valentín sobre a homossexualidade é justamente da ordem do imaginário, uma vez que ele, até então, não teria legitimidade para descrever ou se referir à homossexualidade, já que nunca tomou parte em práticas homossexuais. A relação sexual que ocorre entre Valentín e Molina poderia, então, ser vista como um 'procedimento cognitivo' da parte de Valentín, uma vez que ele necessita experienciar o fato para melhor compreendê-lo? Dificilmente. É praticamente impossível tentar atribuir razões para Valentín ter mantido relações sexuais com Molina, no cárcere, a partir de evidências textuais. O mesmo

1132 Estudos Feministas, Florianópolis, 21(3): 1121-1147, setembro-dezembro/2013 
${ }^{43}$ PUIG, 1994, p. 23.

${ }^{44}$ PUIG, 1994, p. 200, grifo meu. já não pode ser dito do beijo solicitado a Valentín por Molina, o qual sugere uma estima afetiva que se estende além do desejo sexual. Finalmente, o fato de Valentín dar a Molina o beijo solicitado após vários intercursos sexuais instaura uma importante ambiguidade no romance. Esse beijo seria uma demonstração de carinho legítimo por parte de Valentín, ou apenas uma estratégia articulada para convencer Molina a levar informações para seus companheiros de guerrilha?

É importante assinalar a maneira pela qual Valentín manipula as categorias experiência, corpo e ignorância. A natureza do desejo sexual, ainda que atrelado à experimentação do corpo, pode ser conhecida mesmo sem a experimentação: essa é a reivindicação cognitiva de Valentín, ao afirmar que "yo ya sé todo de vos, aunque no me hayas contado nada". ${ }^{43}$ Contudo, o mesmo não se aplica à atividade cognitiva com relação à tortura: somente ao sofrer a tortura tornar-se-ia possível conhecer a tortura. Valentín coloniza a mentalidade cognoscente de Molina, ao legitimar a sua própria imaginação como forma de conhecer a natureza do desejo homossexual, e deslegitimar a imaginação do outro como possibilidade de conhecer a natureza da tortura.

As contradições suscitadas pela ideologia marxista dos revolucionários não passam despercebidas no romance. Em uma das notas de rodapé, quando é apresentada a discussão sobre as maneiras através das quais se operacionaliza a repressão homofóbica nas relações sociais, cita-se a obra de Dennis Altman, o qual, por sua vez, lembra da falência do utópico ideal de que a solução do conflito de classes, através da revolução proletária, resolveria também a questão da opressão sexual e das assimetrias de poder entre homens e mulheres:

Y en cuanto al conveniente, pero sólo ideal - hasta hace pocos años - paralelismo entre las luchas de liberación de clases y las de liberación sexual, Altman recuerda que a pesar de los desvelos de Lenin en favor de la libertad sexual en URSS, por ejemplo el rechazo de la legislación anti-homosexual, estas leyes fueron reintroducidas en 1934 por Stalin, y el prejuicio contra la homosexualidad como una "degeneración burguesa" se afianzó así en casi todos los partidos comunistas del mundo. ${ }^{44}$

Mesmo endossando a opinião de Dennis Altmann acerca da impossibilidade de conciliação entre a libertação das classes e a libertação sexual, a ressalva manifesta pela incisa "hasta hace pocos años" deixa em suspenso uma possibilidade de reavaliar esse paralelo. Tal possibilidade é explorada a partir de um olhar que associa a homossexualidade e 
a revolução como maneiras de rebelião contra estruturas arbitrárias de poder: o olhar da Dra. Anneli Taube.

Tal como Leni Lamaison (a protagonista do filme Destino), Molina assume a persona de uma dramática espiã. Se Leni Lamaison trai sua pátria em nome do amor, Molina expia a impossibilidade de seu amor com a morte durante sua colaboração com a guerrilha. Subentende-se ao final do romance que a trágica morte de Molina, ao levar informações de Valentín para seus companheiros revolucionários, foi uma escolha dele próprio, já que poderia ter escolhido ser pego pela polícia e voltar à prisão como colaborador político dos 'subversivos'. A real consciência de Molina com relação ao teor político dos seus atos pode ser contestada, uma vez que se considere o seu envolvimento com os revolucionários como unicamente promovido pela afeição que sente por Valentín (particularmente depois do beijo trocado pelos dois personagens no cárcere). Na cena final do romance, o próprio Valentín, em seu delírio provocado pela combinação da tortura com a morfina, relativiza a possibilidade de que Molina tenha adquirido alguma consciência política no cárcere:

[...] bueno... me pregunta si es cierto todo eso que sacaron los diários, que murió mi compañero de celda, en un tiroteo, y si fue culpa mía, y si no me dá vergüenza de haberle traído tanta mala suerte, "¿qué le contestaste?", que fue culpa mía, y que estoy muy triste, pero que no hay que ponerse triste porque el único que sabe es él, si estaba triste o estaba contento de morrirse así, sacrificándose por una causa buena, eso solamente lo habrá sabido él, y ojalá [...]. ${ }^{45}$

Esse fragmento dos pensamentos de Valentín é de grande valia para reinterpretar o papel dos jogos de sedução, bem como para reavaliar as dimensões éticas da relação nascida no cárcere. Esse trecho é muito mais revelador do que o tão citado trecho do diálogo que justifica o título do romance:

[Molina] - Tengo una curiosidad... ¿te daba mucha repulsión darme un beso?

[Valentín] - Uhmm... debe haber sido de miedo que te convertieras en pantera, como aquella de la primera película que me contaste.

[Molina] - Yo no soy la mujer pantera.

[Valentín] - Es cierto, no sos la mujer pantera.

[Molina] - Es muy triste ser mujer pantera, nadie la puede besar. Ni nada.

[Valentín] - Vos sos la mujer araña, que atrapa a los hombres en su tela.

[Molina] - iQué lindo! iEso sí me gusta! ${ }^{46}$

1134 Estudos Feministas, Florianópolis, 21(3): 1121-1147, setembro-dezembro/2013 
${ }^{47}$ Pode-se ler, na referência à empresa bananeira do pai desse personagem, um paralelo com a Tropical Plantanera S.A., empresa bananeira presente no romance Viento fuerte (1950), do guatemalteca Miguel Ángel Astúrias (primeiro volume de sua sintomática "trilogia da banana"). Nos outros dois romances da trilogia El papa verde (1954) e Los ojos de los enterrados (1960), é realizada a denúncia das explorações feitas pelas grandes companhias multinacionais em terras latinoamericanas. A imagem de uma despótica companhia bananeira surge também em um episódio de Cien años de soledad (1967) de Gabriel García Márquez. A recorrência desse motivo na literatura latino-americana dos anos 1950 e 1960 refrata o impacto de um importante fato histórico da América Latina no século XX: o assassinato em massa dos trabaIhadores grevistas da United Fruit Company, na cidade de Ciénaga (na Colômbia), massacre ocorrido em 6 de dezembro de 1928. ${ }^{48}$ PUIG, 1994, p. 147, grifo meu.
É mister ressaltar, contudo, que Molina colaborava com o Diretor da Penitenciária, tentando arrancar informações sobre a resistência política com a qual Valentín estava envolvido. De colaborador do regime ditatorial argentino a colaborador da causa revolucionária: não seria tal mudança um motivo suficiente para eximir Molina da acusação de alienação política e frivolidade? Em sua performance, ao transbordar os limites nocionais de gênero e orientação sexual, Molina reinventa os significados da intervenção política a partir de uma estética de si.

A partir de concepções estereotipadas do feminino adotadas por Molina, Valentín percebe o quanto sua própria percepção a respeito das mulheres, que se pretendia libertária, não abarcava a questão do livre exercício da sexualidade. Quando Valentín come uma refeição envenenada, preparada pelos policiais para que, fragilizado, não resista e termine por revelar informações a respeito de seus companheiros, Molina começa a lhe contar outro filme, como forma de lhe amenizar o sofrimento. Nesse filme, um jovem rico, apaixonado por automobilismo e que outrora estudava Ciências Políticas na Sorbonne, é estimulado pelo pai a entrar nas competições profissionais. Ao estimular o gosto do filho pelo automobilismo, o pai assegura-se de que o filho não se envolva com os comunistas e militantes da Sorbonne. Apesar de ter possibilidades para tanto, o filho não aceita ser patrocinado pelas grandes empresas 'capitalistas' que sustentam o automobilismo, preferindo, apesar de todos os reveses, continuar sendo bancado pela empresa bananeira do próprio pai. ${ }^{47} \mathrm{O}$ absurdo desse argumento, que alinha ao mesmo tempo uma postura anticapitalista e um individualismo egoísta, faz com que Valentín se aperceba das próprias contradições que o atormentam: "sí, porque yo ha ... hablo mucho pero ... pero en el fondo lo que me me ... me ... sigue gustando es ... outro tipo de mujer, adentro mío yo soy igual que todos los reaccionarios hijos de puta que me mataron a mi compañero ... Soy como ellos, igualito". ${ }^{48}$

Algumas leituras de El beso de la mujer araña enfatizam o jogo de sedução, no qual Molina supostamente seduziria Valentín tanto erótica quanto ideologicamente, através de seu discurso. Nessa perspectiva, o beijo entre Molina e Valentín seria visto como uma síntese dialética entre dois discursos diametralmente opostos: o camp, representado pelos filmes e boleros tão apreciados por Molina, e o discurso revolucionário, politicamente consciente e comprometido de Valentín. Uma vez que Molina 'politiza-se' ao mesmo tempo que Valentín apercebe-se que possui muitos pontos em comum com os reacionários que tanto critica, uma outra possibilidade de leitura envolvendo a sedução torna-se possível: não teria Valentín seduzido Molina, de forma que 
este colaborasse com seus planos? Ao invés de supervalorizar o gesto de Molina a seduzir Valentín, parece pertinente salientar que há também a possibilidade de que a sedução tenha se dado em sentido oposto. Porque não pensar que Valentín, movido pela necessidade de enviar informações aos seus companheiros, teria manipulado Molina? Parece importante salientar este momento de ambivalência textual, no qual o enredo se coloca como contraponto à síntese possível, assinalada nas notas de rodapé através da menção aos escritos sobre sexualidade e revolução, de autoria da Dra. Anneli Taube.

\section{A voz da margem, a voz na margem}

Mais pertinente do que perguntar 'quem escreve este romance?' ou 'quem nos conta esta história?', seria perguntar 'quais valores são propostos, articulados e/ou questionados por este texto?', questão que permitiria uma leitura do corpus sem cair na cilada de um individualismo biografista. Uma vez que o sujeito é produzido como um efeito da linguagem, ou seja, não se configura como fonte unívoca dos sentidos produzidos por seus falares, considerar o autor como única origem dos sentidos equivaleria a destituir a história, a ideologia e os aparelhos ideológicos de suas forças na construção de significado. Deslocar a pergunta para a questão da focalização e dos valores através dela sustentados permite evitar a ideia de que o autor, pressuposto como a autoridade textual mascarada sob a forma do narrador, seria a única 'consciência' responsável pela produção de sentidos ao longo da narrativa romanesca.

Quase todas as fontes das notas de rodapé de El beso de la mujer araña são factuais, isto é, remetem a documentos e livros que realmente existem no mundo empírico, exterior ao mundo ficcional criado pelo romance. Outras fontes, ainda que em número bastante reduzido, não podem ser consideradas factuais, ou melhor, não dizem respeito a elementos externos. Uma dessas 'fontes bibliográficas ficcionais' é a que aparece no quarto capítulo, remetendo a uma brochura publicitária de divulgação do filme pró-nazista Destino. Nem o documento, nem o filme em questão existem senão no universo diegético do romance, ao contrário de outras obras citadas nas notas sobre homossexualidade, como Sexual Politics, de Kate Millet (1970), e Homosexual: Oppression and Liberation, de Denis Altman (1971). A outra nota de rodapé que remete a uma bibliografia 'fictícia' ou 'imaginária' é a que acompanha o décimo primeiro capítulo, na qual se faz referência ao livro Sexualidad y revolución, de autoria da psicóloga dinamarquesa Anneli Taube. O caráter ficcional desta suposta 'autoridade dinamarquesa em sexologia' foi

1136 Estudos Feministas, Florianópolis, 21(3): 1121-1147, setembro-dezembro/2013 
declarado pelo próprio Manuel Puig em entrevista a Manfred Engelbert e José Amícola:

MANFRED ENGELBERT: ¿Vas a decirnos quién es el científico inventado? Tú en la entrevista con Ronald Christ dices que hay una invención en las notas, dónde expresas algo que sería más bien tu conclusión personal. MANUEL PUIG: La doctora danesa Anneli Taube no existe. (Risas). En la edición danesa le dije: "pongan esse outro nombre, la inglesa tanto..." Y se olvidaron y dejaron la danesa Anneli Taube. (Risas). Pero nadie se dio cuenta de nada. JOSÉ AMÍcOLA: Porque nosotros estuvimos buscando, pero, como hay varios libros que no encontramos, entonces quedaba abierta la duda. MANUEL PUIG: Sí, es ella. ${ }^{49}$

Através das ideias da sexóloga dinamarquesa, é realizada uma espécie de síntese entre o pensamento revolucionário e as teorizações sobre homossexualidade. Antes, porém, de se adentrar na discussão sobre as reverberações das opiniões de Taube para a interpretação do romance, cabe discutir um pouco as implicações produzidas pela inclusão de notas de rodapé, um tipo de escrita característica do discurso científico - e de outras modalidades não ficcionais de discurso - em uma obra de ficção. Não é apenas o fictício livro da fictícia Dra. Anneli Taube, intitulado Sexualidad y revolución, que associa o livre exercício da sexualidade a uma postura libertária, subversiva e revolucionária. Tal postura é análoga àquela apresentada pelo próprio romance em questão, El beso de la mujer araña. Se é verdade que não há um narrador explícito a organizar a narrativa, não o é afirmar que o romance está desprovido de um ponto de vista coerente e bem estruturado. Entendendo a noção de sujeito como a construção de um interesse, a Dra. Anneli Taube pode ser vista, senão como uma focalizadora (uma vez que suas opiniões e seus escritos não mantêm uma relação direta com o enredo romanesco), ao menos como um vetor ideológico para os valores articulados pelo narrador das notas de rodapé. Através do apreço que este narrador extradiegético tem para com a sexóloga dinamarquesa, é possível asseverar que ele subscreve suas posturas e ideias (no que diz respeito a essa compreensão de processos análogos entre práticas sexuais e posturas políticas revolucionárias).

A necessidade de se levantar tal discussão se dá pelo fato de imperar, entre os críticos especializados da obra de Manuel Puig, a interpretação de que as notas de rodapé efetivamente tenham um caráter 'científico'. Isso equivale a dizer que o papel das notas seria o de remeter a um mundo externo, no qual ocorrem efetivamente as discussões acerca da homossexualidade, e que sua presença indicaria tão 
${ }^{50}$ ECHEVARRÉN, 1978, p. 74.

51 ECHEVARRÉN, 1978, p. 75.

${ }^{52}$ AMíCOLA, 1992, p. 95. somente um apelo ao discurso científico para legitimar, de alguma forma, o tema da homossexualidade no romance. Para Roberto Echevarrén, as notas teriam um papel 'didático', uma vez que traduziriam, para o leitor não especializado, as teorias sobre a homossexualidade, afastando-o do senso comum homofóbico. De acordo com Echevarrén:

[Las notas al pie de la página] tal vez irriten a ciertos lectores, tal vez resulten en parte superfluas a otros. El propósito fundamental de las notas es enriquecer la visión de la homosexualidad abriendo un campo de posibilidades que rebasa las características concretas del personaje Molina. ${ }^{50}$

O recurso a essa modulação discursiva 'científica' das notas de rodapé é, para outros críticos, como José Amícola, responsável também por distanciar o leitor dos personagens, uma vez que a presença constante das notas 'recorda' ao leitor o fato de estar diante de 'seres de papel', de personagens, evitando assim o seu envolvimento e sua identificação ou com Valentín, ou com Molina, em um gesto interpretativo maniqueísta. Segundo Echevarrén, "la mayor ventaja das notas es la distáncia que establecen entre una homosexualidad 'posible' y el 'modelo reducido' de la homosexualidad de Molina". ${ }^{51}$ Para Amícola, por sua vez, "las notas tienen la cualidad de establecer una connivencia con el lector mediante un efecto de ruptura de la ilusión que, a la manera brechtiana, permite considerar el problema desde la perspectiva de una equidistante lectura racional". ${ }^{52}$

O ponto problemático presente nessas interpretações - vê-las como uma presença científica a 'contaminar' a escrita literária, provocando um distanciamento brechtiniano (de acordo com Amícola), ou a funcionar como um discurso de caráter didático, ao lembrar ao leitor que os modelos identitários para homens homossexuais não se restringem ao apresentado por Molina (segundo a observação de Echevarrén) - está no status atribuído às notas de rodapé. Não se pode esquecer que as notas, quando presentes em uma obra de ficção, estão subordinadas ao discurso ficcional, ao universo diegético erguido através da escrita literária, e não o inverso. Shari Bradstock, ao refletir sobre o papel das notas de rodapé em textos literários, afirma o seguinte:

Footnotes in ficcional texts do not necessarily follow the rules that govern annotation in non-ficcional texts: they may or may not provide citation, explication, elaboration, or definition for an aspect of the text; they may or may not follow "standart form"; they may or may not be subordinated to the text to which they are appended. Most significantly, they belong to a ficcional universe, steam from a creative act rather than a critical one, and direct themselves toward the ficcion and never

1138 Estudos Feministas, Florianópolis, 21(3): 1121-1147, setembro-dezembro/2013 
${ }^{53}$ Shari BENSTOCK, 1993, p. 204205, tradução minha.

\begin{abstract}
toward an external construct, even when they cite "real" works in the world outside the particular ficcion. The referencial and marginal features of these notes serve a specifically hermeneutic function: to the extend that notations in ficcional texts negotiate the distance between writer and reader, and that they do so in terms that differ radically from those of scolarship discourse. [As notas de rodapé nos textos ficcionais não necessariamente seguem as regras que governam o uso de notas em textos não ficcionais: elas podem ou não inserir citações, explicações, elaborações ou definições para um determinado aspecto do texto; elas podem ou não seguir o "formato padrão"; elas podem ou não estar subordinadas ao texto do qual são apêndices. Mais importante ainda, elas pertencem a um universo ficcional, são emanações originárias de um ato criativo de um sujeito criativo, e remetem diretamente a si mesmas, nunca a um suposto exterior desse universo ficcional, mesmo quando elas citam escritos "reais" pertencentes a um mundo exterior a esta ficção específica. A característica referencial e marginal das notas serve apenas a uma função hermenêutica: ao fato de que, em um texto ficcional, notas de rodapé negociam a distância entre autor e leitor, e que elas o fazem em termos radicalmente diferentes daqueles do discurso acadêmico]. ${ }^{53}$
\end{abstract}

Essa perspectiva obriga a uma revisão das ideias de Amícola e Echevarrén. O recurso à legitimidade do discurso do outro é performativizada pelas notas apenas no discurso científico, cabendo às notas de rodapé uma função completamente diferente no discurso ficcional. Retomando a figura de Anneli Taube, fica evidente a função das notas no romance de Puig: elas funcionam como uma paródia subversiva da legitimidade do discurso científico. Ao colocar uma sexóloga ficcional ao lado de vários pensadores da sexualidade, El beso de la mujer araña questiona o próprio status do discurso científico que reivindica a primazia epistemológica de produzir o verdadeiro conhecimento sobre a sexualidade. Em última análise, o resultado dessa subversiva paródia da escrita científica é o de colocar o discurso da 'ciência', tida como a legítima produtora de saberes sobre a sexualidade, no campo das práticas ficcionais reguladoras.

\section{Considerações finais: performatividade} e subversão sexual

Tal como o diálogo estabelecido entre Valentín e Molina, todo o conhecimento científico acumulado nas oito longas notas de rodapé é colocado em suspenso, da mesma forma que a presumida e segura heterossexualidade de 
54 Michel FOUCAULT, 1988.

${ }^{55}$ Nascido em um contexto estadunidense de combate à AIDS em plena Ronald Reagan's Age, o ACT UP!, atualmente, configura-se como um grupo de intervenção política descentralizado e de caráte transnacional. Para maiores informações, acessar os sites: <www. actuporalhystory.org $>,<$ www.actupny org $>$, $<$ www.actupparis.org $>,<w$ ww.actupsf.com $>$, e $<$ www.actup .co.uk > .
Valentín. Anneli Taube, citada por esse narrador invisível e impessoal (o qual gerencia a enunciação nas notas de rodapé), põe em questão as tentativas de normalização produzidas pelo discurso científico, no mesmo momento em que a heterossexualidade de Valentín, a partir de sua performance de gênero e de suas práticas sexuais, torna-se algo completamente singular, da ordem do questionamento das premissas heteronormativas. Se os limites de gênero são subvertidos, parodiados e desnaturalizados pela performance de gênero estilizada por Molina, os limites entre homossexualidade e heterossexualidade são também subvertidos, parodiados e desnaturalizados por Valentín. Finalmente, a própria legibilidade dos limites entre discurso científico e discurso ficcional é borrada, rasurada e deslocada pela presença de uma sexóloga ficcional, cujo discurso imiscuise ao dos pensadores 'factuais' da homossexualidade.

A desestabilização do discurso científico provocada pelas notas de rodapé questiona o status de verdade e objetividade desse discurso. Em outras palavras, a retórica da literatura mostra-se um mecanismo eficiente para reinventar os corpos e os prazeres, através de uma modulação livre das determinações de uma matriz binária de identidades de gênero e de sexualidade. Cabe relembrar Michel Foucault, quando afirma, a respeito das relações entre sexo e discurso, que se tratam menos de um discurso sobre o sexo do que de uma multiplicidade de discursos, produzidos por toda uma série de mecanismos que funcionam em diferentes instituições. ${ }^{54}$ Ao estabelecer relações entre a sexualidade e a revolução política, a subversão das potencialidades eróticas é politizada ao mesmo tempo que a noção de política é reinventada. Fora do contexto de análise e de crítica literária, pode-se pensar nas intervenções públicas de grupos como o ACT UP! (AIDS Coalition To Unleash Power! $)^{55}$ e no fato de que é o contexto imediato que determina o teor político de uma intervenção. Arremessar uma bolsa de sangue em um prédio público (uma das mais polêmicas manifestações de política performativa do ACT UP!) pode não aparentar nada de político se tomado como fato isolado, mas o mesmo ato, em uma manifestação pública na década de 1980, nos primórdios da epidemia de AIDS (quando homossexuais, usuários de drogas injetáveis e hemofílicos eram considerados os grandes grupos de risco), satura-se de significados políticos. Em especial quando se tem em mente que, naquele momento, o serviço de saúde pública estadunidense não amparava tratamento para HIV-AIDS, atitude alicerçada no puritanismo que caraterizou a política de Ronald Reagan.

A discussão sobre a elaboração de novas agendas políticas emerge como uma das questões centrais na literatura latino-americana no cenário da crítica contemporânea.

1140 Estudos Feministas, Florianópolis, 21(3): 1121-1147, setembro-dezembro/2013 
${ }^{56}$ Mary-Louise PRATT, 2004, não paginado, tradução minha. Aconferência "Los imaginarios planetários" foi apresentada no IXCongresso Internacional da Associação Brasileira de Literatura Comparada, na Universidade Federal do Rio Grande do Sul, em 19 de julho de 2004. Cabe aqui registrar meus agradecimentos à Mary-Louise Pratt, por ter gentilmente cedido uma cópia do texto apresentado em sua conferência, o qual permanece, até o momento, inédito.

57 PRATT, 2004, não paginado, tradução minha.
Mary-Louise Pratt, durante o IX Colóquio Internacional da Associação Brasileira de Literatura Comparada, afirmou que, em todos os lugares do planeta, grandes setores da humanidade vivem sabendo ser as suas existências redundantes e desnecessárias para o funcionamento de uma ordem econômica planetária cujos contornos - definidos pela lógica do mercado e do capital - são conhecidos claramente até mesmo para aqueles que de tal ordem se veem excluídos. Pratt endossa a opinião de que tais sujeitos não apenas se sabem excluídos dessa nova ordem mundial, mas também não cultivam esperanças de nela entrar:

[...] las nuevas formaciones religiosas, tanto como la proliferada literatura de autoayuda cuya despolitización tanto desespera a los intelectuales, demuenstran la aparición de sujetos y saberes en espacios donde el humanismo ilustrado y la interpelación cívica ya no llegan o nunca llegaran. ${ }^{56}$

Cabe rememorar as palavras de Pratt sobre as alternativas mobilizadas por estes sujeitos sociais à margem dos processos de mundialização:

En algunos aspectos estos nuevos saberes y formas de sujetividad son funcionales para el capitalismo - se cita com frecuencia su capacidad de racionalizar la autoexplotación, por ejemplo, o de instalar un individualismo desagregador, o de desviar a las personas de proyectos políticos y de solidariedad. Pero en otros aspectos los nuevos saberes constituyem maneras de ser y de vivir a contracorriente de los dictados del mercado y los valores del consumo. Subrayo: no es mi intención ni idealizar ni trivializar ni homogeneizar estas formaciones, sino reconocer que está allí, y que surgen de un vacío semántico, que la restruturación neoliberal genera y no resuelve. ${ }^{57}$

Da mesma forma que a literatura de autoajuda é compreendida por Pratt como uma maneira de ser e de viver a contrapelo das hegemonias políticas e econômicas, a performance de gênero de Molina pode ser lida como uma possibilidade de resistência à hegemonia da heteronormatividade, mantenedora de uma matriz binária de gênero. Não seria exagero considerar o apelo de Molina ao kitsch e ao camp - tendências estéticas massivas continuamente reapropriadas pelas subculturas gays em âmbito transnacional como uma tentativa "de ser e de viver na contracorrente" dos pressupostos de mercado e de uma heteronormatividade transnacional, superando a dicotomia entre 'burguesia e proletariado', 'heterossexualidade e homossexualidade', 'masculinidade e feminilidade'. Instaurando uma paródia performativa da feminilidade hegemônica, Molina consegue 
${ }^{58}$ PUIG, 1994, p. 207.

rearticular as relações de gênero e as definições de sexualidade; mas a rearticulação não termina aí: as motivações políticas de Valentín ao optar pela guerrilha, tidas em princípio como um ideal nobre, elevado e isento de personalismos, são denunciadas também como uma possível resposta individual, como no caso de Pedro, que ingressa na guerrilha motivado unicamente pelo desejo de vingar-se da própria mãe e de reabilitar o nome do pai. À premissa feminista 'o pessoal é político', cumpriria acrescentar a de que 'o político sempre é uma questão pessoal'.

Tal reflexão é fundamental para retomar a discussão sobre as motivações de Molina e Valentín em sua relação. A intenção é a de sugerir que os saberes articulados por Molina, tais como o sentimentalismo hollywoodiano e as convenções tradicionais do papel feminino na sociedade, são recodificados a partir do momento em que se adaptam a uma cultura minoritária como o gueto homossexual. Se o discurso transnacional do movimento de liberação homossexual torna-se, nos anos 70 do século XX, o discurso hegemônico a normativizar padrões de comportamento homossexual, o perfil demodée de Molina (assinalado por Alan Pauls) caracteriza-se não como uma maneira retrógrada de se vivenciar a homossexualidade, mas sim como uma maneira de contestar os padrões de masculinização das identidades homossexuais. Pode-se contemplar essa questão no seguinte fragmento de diálogo:

[Molina] - Sí, pero mirá, mis amigos han sido siempre ... putazos, como yo, y nosotros entre nosotros, ¿cómo decirte?, no nos tenemos en demasiada confianza, porque nos sabemos muy ... miedosos, flojos. Y siempre lo que estamos esperando ... es la amistad, o lo que sea, de alguien más serio, de un hombre, claro. Y eso nunca puede ser, porque un hombre, lo que quiere es una mujer.

[Valentín] - ¿Y todos los homosexuales son así?

[Molina] - No, hay otros que se enamoran entre ellos. Yo y mis amigas somos mu-jer. Esos jueguitos no nos gustan, esas son cosas de homosexuales. Nosotras somos mujeres normales que nos acostumbramos con hombres. ${ }^{58}$

O que estaria por trás da masculinização (ou da feminilização) da homossexualidade masculina? Não haveria nesse processo a rearticulação do preconceito de gênero sob o verniz de uma demanda anti-homofóbica? Talvez a reivindicação de Molina de pertencer ao gênero feminino sinalize exatamente a contestação dessa identidade sexual emergente, na qual a hipermasculinização, em certa medida, reproduz, nas relações estabelecidas entre homossexuais 'efeminados', de um lado, e

1142 Estudos Feministas, Florianópolis, 21 (3): 1121-1147, setembro-dezembro/2013 
${ }^{59}$ PUIG, 1994, p. 210-211.

${ }^{60}$ PUIG, 1994, p. 210-211.

${ }^{61}$ PUIG, 1994, p. 285. homossexuais 'másculos', de outro, as mesmas assimetrias historicamente consagradas pelo patriarcado nas relações travadas entre homens e mulheres. Para a fictícia Dra. Anneli Taube, também é evidente o imbricamento da opressão de gênero com a heteronormatividade:

Ahora bien la doctora Taube, después de valorizar el motor primero de la homosexualidad y señalar su característica de inconformismo revolucionario, observa que la ausencia de otros modelos de conducta [...] hace que el futuro homosexual varón, por ejemplo, después de rechazar los defectos del padre opresor, se sienta angustiado por la necesidad de identificación con alguma forma de conducta y "aprenda" a ser sometido como su madre. ${ }^{59}$

Ao adotar a perspectiva da Dra. Anneli Taube para analisar a postura de Molina, fica evidente que sua identificação com a mãe - e com uma identidade feminina em geral - implica uma contestação do signo da opressão, simbolizado pela figura paterna - e pela masculinidade em geral. Todavia, a consequência dessa oposição ao papel do opressor é a de uma identificação com o papel do oprimido, isto é, com o gênero feminino tal como descrito pelos esquemas patriarcais. Ainda na esteira do trabalho intelectual de Anneli Taube, tal situação "empezó a cambiar en la década de los sesenta, con la irrupción del movimiento de liberación femenina, ya que el consiguiente enjuiciamiento de los roles 'hombre fuerte' y 'mujer débil' desprestigió ante los ojos de los marginados sexuales esos modelos tan inalcanzables como tenazmente imitados". 60

Se os papéis sociais de 'homem forte' e 'mulher frágil' são imitações repetidas por homossexuais - sejam homens ou mulheres - isso implica pensar que esses modelos são imitações condicionadas dentro de um regime heteronormativo, imitações de uma masculinidade e de uma feminilidade idealizadas, desligadas do mundo material, mesmo quando performativizadas por homens e mulheres heterossexuais. A imitação do feminino realizada por Molina pode ser considerada reacionária em certos aspectos, afinal, ela está baseada nas representações hollywoodianas da feminilidade. Mas ela possui um aspecto que extrapola o estereótipo das divas do cinema: uma vez que a femme fatale é reinventada por Molina de modo a colaborar na resistência a um regime totalitário - a ditadura argentina -, ele executa um processo de transculturação no qual a femme fatale, ao invés de espiã nazista, torna-se colaboradora da guerrilha. Como afirma Valentín, "el único que sabe es él, si estaba triste o estaba contento de morrirse así, sacrificándose por una causa buena, eso solamente lo habrá sabido él". ${ }^{61}$ 
${ }^{63}$ DE LAURETIS, 1884, p. 106 , tradução minha.
De acordo com Teresa de Lauretis, "the relation of narrative and desire must be sougth within the specificity of a textual practise, where it is materially inscribed" [a relação entre narrativa e desejo deve ser buscada no interior da especificidade de uma prática textual, no qual ela é materialmente inscrita]. ${ }^{62}$ Pensar o desejo implicado na estrutura narrativa requer, por extensão, considerar que "the very work of narrativity is the engagement of the subject in certain posicionalities of meaning and desire" [o trabalho fundamental da narratividade é o engajamento do sujeito em determinadas posicionalidades de sentido e de desejo]. ${ }^{63} \mathrm{~A}$ articulação de uma narrativa sempre se dá a partir de uma posicionalidade do sujeito, a qual envolve o desejo e a produção de significados. Puig, ao deslocar o narrador para as notas de rodapé, coloca os significados instituídos pelo discurso ficcional em paridade com o discurso científico sobre a homossexualidade, como estratégia para legitimar a enunciação de seu narrador (que subscreve a ideia de que a homossexualidade pode configurar um posicionamento revolucionário). Ao mascarar - locus do narrador através da criação de uma sexóloga fictícia, o narrador de Puig reivindica um terceiro espaço de produção de saber, no qual é possível a síntese entre a revolução política e a revolução sexual.

\section{Referências}

ALÓS, Anselmo Peres. "Narrativas da sexualidade: pressupostos para uma poética queer". Revista Estudos Feministas, v. 18, n. 3, p. 837-864, 2010. . "Gênero, epistemologia e performatividade: estratégias pedagógicas de subversão". Revista Estudos Feministas, v. 19 , n. 2, p. 421-449, 2011 a. ."Prolegomena queer: gênero e sexualidade nos estudos literários". Cadernos de Letras da UFF, n. 42, p. 199 - 217, $2011 \mathrm{~b}$.

ALTMAN, Dennis. Homosexual: Oppression and Liberation. New York: New York University Press, 1993 [1971].

AMícOLA, José. Manuel Puig y la tela que atrapa al lector. Buenos Aires: Grupo Editor Latinoamericano, 1992.

. "Los manuscritos". In: PUIG, Manuel. El beso de la mujer araña. Edición crítica coordenada por José Amícola y Jorge Panesi. Méjico: ALLCA XX, 2002, p. XIXXXXII.

ASTÚRIAS, Miguel Ángel. Viento fuerte. Alianza Editorial: Madrid, 1950.

El papa verde. Alianza Editorial: Madrid, 1954. 960 .

1144 Estudos Feministas, Florianópolis, 21(3): 1121-1147, setembro-dezembro/2013 
BAL, Mieke. Narratology. 2nd Extended Edition. Buffalo and New York: The University of Toronto Press, 1997.

"Poetics, Today." Poetics Today. v. 21, n. 3, Fall, p. 479-502, 2000.

BASSNETT, Susan. Estudos de tradução. Trad. Paula A. R. Antinolfi, Letícia V. Abreu e Sônia T. Gehring. Porto Alegre: UFRGS Editora, 2005.

RODRIGUES, Sara Viola. "Literatura comparada e estudos de tradução: um percurso e algumas perspectivas". In: BEHAR, Lisa; COUTINHO, Eduardo; RODRIGUES, Sara Viola (Orgs.). Elogio da lucidez: a comparação literária em âmbito universal. Porto Alegre: Evangraf/Instituto de Letras da UFRGS, 2004. p. 381-389.

BENSTOCK, Shari. "At The Margin of Discourse: Footnotes in The Ficcional Text." PMLA, v. 2, n. 98, p. 204-215, 1993.

BERSANI, Leo. Homos. Cambridge: Harvard University Press, 1995.

BUTLER, Judith. Bodies That Matter: On The Discursive Limits of "Sex." London: Routledge, 1993.

Problemas de gênero: feminismo e a subversão da identidade. Trad. Renato Aguiar. Rio de Janeiro: Civilização Brasileira, 2003.

BUTLER, Judith. "Is Kinship Always Already Heterosexual?" In: 102-130. Undoing Gender. London: Routledge, 2004a. p. . Undoing Gender. London: Routledge, 2004b.

CARVALHAL, Tania Franco. O próprio e o alheio: ensaios de literatura comparada. São Leopoldo, RS: UNISINOS, 2003.

DE LAURETIS, Teresa. Alice Doesn't: Feminism, Semiotics, Cinema. Bloomington and Indiana: Indiana University Press, 1984.

ECHEVARRÉN, Roberto. "El beso de la mujer araña y las metáforas del sujeto" Revista lberoamericana, v. 44, n. 102-103, p. 65-75, 1978.

"Género y géneros." In: PUIG, Manuel. El beso de la mujer araña. Edición crítica coordenada por José Amícola y Jorge Panesi. Méjico: ALLCA XX, 2002. p. 456-462.

ESPERANZA, Graciela. "Del escritor como contrabandista". In: PUIG, Manuel. El beso de la mujer araña. Edición crítica coordenada por José Amícola e Jorge Panesi. Méjico: ALLCA XX, 2002. p. 550-563.

EURÍPEDES. Medéia. Trad. Mario da Gama Kury. Rio de Janeiro. Jorge Zahar Editor, 1991.

FOUCAULT, Michel. História da sexualidade: a vontade de saber. 10. ed. São Paulo: Graal, 1988.

GARCÍA MÁRQUEZ, Gabriel. Cien años de soledad. Editorial Sudamericana: Buenos Aires, 1967.

JILL-LEVINE, Suzanne. Manuel Puig. Buenos Aires: Seix Barral, 2002. 
LAIRD, John. The Idea of Value. Cambridge: Cambridge University Press, 1929.

LOPES, Denilson. "Terceiro manifesto camp". In: . 0 homem que amava rapazes e outros ensaios. Rio de Janeiro: Aeroplano, 2002, p. 95-100.

MASIELLO, Francine. "Fuera de lugar: silencios y desidentidades en El beso dela mujer araña". In: PUIG, Manuel. EI beso dela mujer araña. Edición crítica coordenada por José Amícola y Jorge Panesi. Méjico: ALLCA XX, 2002. p. 579-589.

MILLET, Kate. Sexual Politics. New York: Doubleday, 1970.

O GRANDE AMOR (Die Grosse Lieb). Direção de Rolf Hansen. Elenco: Zara Leander, Grethe Weiser, Viktor Staal, Wolfgang Preiss e Victor Janson. Alemanha, 1942. (102 min) 35 mm.

PAULS, Alan. "Inventar la contemporaneidad". In: PUIG, Manuel. El beso de la mujer araña. Edición crítica coordenada por José Amícola y Jorge Panesi. Méjico: ALLCAXX, 2002, p. xvi-xvii.

PELL, Orlie A. Value: Theory and Criticism. New York: New York University Press, 1930.

PERLONGHER, Néstor. "Molina y Valentín: el sexo de la araña". Tiempo Argentino. Buenos Aires, 29 jun. 1986, Caderno Cultura, p. 3-4.

PERRY, Ralph B. General Theory of Value. New York: New York University Press, 1926.

PRATT, Mary-Louise. "Los imaginarios planetarios". Conferência apresentada no IX Congresso Internacional da Associação Brasileira de Literatura Comparada. Universidade Federal do Rio Grande do Sul, Porto Alegre, 19 jul. 2004.

PUIG, Manuel. O beijo da mulher aranha. Trad. Gloria Rodríguez. Rio de Janeiro: CODECRI, 1980.

O beijo da mulher-aranha. Trad. Gloria Rodríguez. São Paulo: Círculo do Livro, 1981.

. O beijo da mulher aranha. 14 ed. Trad. Gloria Rodríguez. Rio de Janeiro: Rocco, 1986. 1994 . El beso de la mujer araña. New York: Vintage Books,

. El beso de la mujer araña. Edición crítica coordenada por José Amícola y Jorge Panesi. Méjico: ALLCAXX, 2002.

SANGUE DE PANTERA (Cat People). Direção de Jacques Tourneur. Elenco: Simone Simon, Kent Smith, Tom Conway, Jane Randolph e Jack Holt. Estados Unidos, 1942. (73 min) $35 \mathrm{~mm}$.

SEDGWICK, Eve Kosofsky. Between Men: English Literature and Male Homosocial Desire. New York: Columbia University Press, 1985.

"Axiomatic." In: The Epistemology of The Closet. Berkeley: The University of California Press, 1990. p. 1-63. SONTAG, Susan. "Notas sobre o camp". In: Contra a

1146 Estudos Feministas, Florianópolis, 21(3): 1121-1147, setembro-dezembro/2013 
interpretação. Trad. Ana Maria Capovilla. Porto Alegre: L\&PM, 1987, p. 318-337.

THOMAS, Calvin (Ed.). Straight with a Twist: Queer Theory and the Subject of Heterosexuality. Urbana and Chicago: The University of Illinois Press, 2000.

YAKER, Daniel; PUIG, Manuel. "Kiss of the Spider Woman: Manuel Puig." Interview. p. 208, Sept., 1985.

WARREN, Austin; WELLEK, René. "Literatura e estudo da literatura". In: Teoria da literatura. 2 ed. Lisboa: Europa-América, 1971a. p. 17-24.

"Valoração". In: . Teoria da literatura. 2. ed. Lisboa: Europa-América, 1971b. p. 301-318.

WITTIG, Monique. "The Straight Mind." In: The Straight Mind and Other Essays. Boston: Beacon Press, 2002. p. 21 32.

[Recebido em $1^{\circ}$ de dezembro de 2011 , reapresentado em 23 de maio de 2012 e aceito para publicação em 12 de setembro de 2012]

\begin{abstract}
Marginal Sexualities at the Borders of the Text: Cinema, Politics and Gender Performativity in El Beso de La Mujer Araña

Abstract: this paper aims to discuss some ambivalent relations between cinema, politics and gender performativity in El beso de la mujer arena [The Kiss of The Spider Woman], an Argentinian novel written by Manuel Puig and first published in 1976. Although this novel was not the first one to discuss gender and homosexuality in the context of Latin American literature, it presents a narrative plot particularly subversive when it comes to the representation of ruptures into the heteronormative beliefs.
\end{abstract}

Key Words: Gender; Performativity; Manuel Puig; Cinema; Latin American Literature. 